\title{
EL VIAJE A ITALIA EN LAS OBRAS DE CERVANTES: ¿FICCIÓN O AUTOBIOGRAFIA?
}

\author{
Luigi Monga \\ Universidad de Vanderbilt. Nashville. Tennessee. Estados Unidos.
}

Muy raros son los diarios de viaje de España a Italia que se publicaron en el siglo XVI. Aunque los lazos, los contactos personales y literarios entre estos dos países fueran estrechos desde finales del siglo XIV hasta el siglo $\mathrm{XVI}$, hay pocos textos que nos describen la realidad cotidiana de verdaderos viajes a Italia. ${ }^{1}$ Es difícil darse cuenta de la razón por qué tenemos tan pocos textos literarios o diarios a Italia de todos los viajeros, políticos, religiosos y soldados que realizaron este viaje: quizás nadie se preocupó por buscar y publicar esos manuscritos.

En el curso de tres siglos, desde el Siglo XIV (pensamos en Chaucer y Petrarca), el viaje a Italia y desde Italia era, según Peter Burke, "la manera más directa y personal para propagar el humanismo”. ${ }^{2}$ En el siglo XIV Antonio de Nebrija nos dijo las causas por las que la mayoría de sus contemporáneos iban a Italia ("para ganar rentas de la Iglesia, para traer fórmulas de Derecho Civil, para trocar mercaderías"); otros, como Nebrija mismo que permaneció allá diez años, iban a Italia por razones intelectuales: "para que por la lei de la tornada después de luengo tiempo restituiesse en la possesión de su tierra perdida los autores del latín que estavan ia muchos siglos desterrados de España". ${ }^{3}$ Viajes y estancias en Italia se vieron facilitados por la fundación de colegios espanoles en Bolonia y en otras universidades; los concilios de Pavía y Siena, de Ferrara, de Florencia y Roma atrajeron a muchos hombres españoles de la Iglesia; nobles, guerreros y cortesanos 
(poetas, músicos y artistas) se quedaron en la corte de Nápoles o de Milán, o cerca de la casa Borgia en Roma.

Por supuesto, algunos humanistas italianos llegaron a España en el siglo XV, a la corte de los Reyes Católicos: nuncios y embajadores, catedráticos, poetas, filósofos y navegantes: claro que no hay que olvidar a Cristóbal Colón... Américo Vespucio, que llegó a España en calidad de businessman de los Médicis; Pedro Mártir de Anglería... En el siglo siguiente tenemos que mencionar, por lo menos, a Baldessar Castiglione y Francesco Guicciardini... "Cualquiera que fuese la impresión que merecía el panorama cultural español a los humanistas llegados de Italia, en tiempos del Emperador la visita a España era casi obligada para cualquier europeo culto; por supuesto, esa situación cambió de forma radical, y en las dos direcciones, merced a la política de puertas cerradas impuesta por Felipe II desde 1559". ${ }^{4}$ En el primer volumen de su antología Viajes de extranjeros por España y Portugal, José García Mercadal nos ofrece un panorama de relaciones y diarios de viajeros: León de Rosmithal, Jerónimo Münzer, Antonio de Lalaing, unos embajadores venecianos, Guicciardini y Navagero, Juan de Vandenesse, y muchos otros. En efecto, los viajeros españoles a Italia eran numerosos en este período histórico, cuando el imperio hapsburgo iba eliminando en Pavía la influencia francesa y estableciendo en Italia su pax hispanica con el tratado de Cateau-Cambrésis, España ya dominaba casi totalmente la vida política y militar en Italia, de Sicilia a Milán.

En el Siglo de Oro el camino es, por lo menos, un elemento importante en la vida literaria de España. "Caballeros andantes verdaderos", según la definición del Quijote, soldados, diplomáticos, estudiantes, y religiosos, no quedaban de "mesurar la tierra ... al sol, al frío, al aire, a las inclemencias de cielo, de noche y de día, a pie y a caballo ... con [sus] mismos pies". ${ }^{6}$ A ellos podemos añadir otra categoría social, la de los picaros, un grupo quizás menos importante en el ámbito de las categorías sociales de la vida cotidiana del país, pero con una presencia muy vivaz en la vida literaria de este período: $¡ O$ pícaros de cocina, sucios, gordos y lucios; pobres fingidos, tullidos falsos, cicaturuelos de Zocodover y de la plaza de Madrid, vistosos oracioneros, esportilleros de Sevilla, mandilejos de la hampa, con toda la caterva innumerable que se enciera debajo deste nombre pícaro...?

"Caballero andante verdadero", soldado, prisionero y viajero, Miguel de Cervantes no deja de viajar por Europa. A pesar de que su viaje a Italia, realizado hacia finales de 1568 al séquito del legado papal Giulio Acquaviva, ${ }^{8}$ no esté directamente documentado en las obras del gran escritor español, es posible ver sus principales elementos reflejados, a veces, en algunas de sus 
obras más específicamente literarias. No tenemos información directa sobre el itinerario de Giulio Acquaviva, de Madrid a Barcelona, y después, a través de la Provenza, a Turín, Milán, Florencia y Roma:' fue, más o menos, el itinerario tradicional, que había seguido, cincuenta años antes, un anónimo mercader milanés cuyo diario publicamos hace diez años. ${ }^{10}$ Cervantes, joven todavía inexperto de la vida y que tenía limitadas lecturas, nos dice muy poco de la experiencia que vivio."

Su itinerario, de una ciudad a otra, puede ser menos importante que la reacción que debe haberse producido en el viajero y de los recuerdos más o menos indelebles que tendrá el escritor en su subconciencia y que se encuentran otra vez en su obra. Los trabajos de Persiles y Segismunda, "esta complicada máquina" 12 escrita cincuenta años después del viaje de Cervantes a Italia, parece ofrecer algunos elementos de un viaje a Italia, por tierra, desde Barcelona hasta la Provenza. Manuel de Foronda, en su obra Cervantes viajero, busca en el Persiles algunas alusiones autobiográficas a las etapas del itinerario del autor del Quijote que seguía al legado Acquaviva. Pero el intento análitico de estudiar los detalles corográficos y los topónimos ${ }^{13}$ no nos ha permitido hasta ahora ofrecer una síntesis de este fenómeno. Es evidente que Cervantes no pudo olvidar el viaje a Italia que hizo en su juventud cuando describió las fantásticas aventuras y peregrinaciones de sus personajes.

Es una lástima para el estudio de "caminería" y de "odepórica" que los elementos geográficos en el Persiles estén sepultados en la anecdótica y en la abundancia de la narración. Los datos de su itinerario, aun los topónimos, son frecuentemente olvidados por el autor, que prefiere favorecer el cuento fantástico y fabuloso y la aventura.

Lo que pasa en el curso del viaje está habitualmente excluido del texto: "otras algunas cosa les sucedieron en el camino de Barcelona, pero** [check] no de tanta importancia que merezcan escritura" (p. 360). Eso es normal en la mayoría de los diarios de viaje del siglo XVI y XVII, porque los autores prefieren hablar de las ciudades que visitan y de las mirabilia urbis, olvidando el viaje y sus banales vicisitudes. Aun la descripción de las ciudades por las que el viajero ha pasado es mínima: hay pocos detalles de Barcelona, Perpiñán (que entonces todavía pertenecía a España) y de varios mesones del Rosellón que no pueden identificarse. El itinerario mismo está ràpidamente resumido: "determinaron de salir de Francia por el Delfinado, y atravesando el Piamonte y el estado de Milán, ver a Florencia ${ }^{14}$ y luego a Roma" (p. 399). 
Sólo Milán, gracias a su reputación económica y estratégica, merece alusiones más detalladas: "admiróles la grandeza de la ciudad, su infinita riqueza, sus oros, que allí no solamente hay oro, sino oros; sus bélicas herrerías [...], la abundancia infinita de sus frutos, la grandeza de sus templos, y finalmente la agudeza del ingenio de sus moradores" (p. 400). Pero justo en Milán Cervantes comete un error muy grave, poniendo en la capital lombarda la "Accademia degli Intronati" que estaba en Siena. Y de Milán, no sabemos si por el difícil camino de Génova, "s o por otro puerto del Apenino, nuestro viajero pasa directamente a Lucca, "ciudad pequeña, pero hermosa" (p. 402), donde se queda cuatro días. Desde Lucca a Acquapendente y después a Roma, el itinerario está apenas dibujado, mencionando sólo un anónimo mesón "abundantemente proveíd[o]" (p. 415) en el cual los viajeros encuentran un estudioso español. Y finalmente entran en Roma por la Porta del Popolo, "besando primero una y muchas veces los umbrales y márgenes de la entrada de la ciudad santa" (p. 427). Pero en Roma también, si excluimos su rápida mención de la visita de las iglesias más famosas ("anduvieron las estaciones con pompa y majestad", p. 437), lo que más importa a Cervantes en la economía de su novela me parece todavía el deseo de contarnos nuevas aventuras y encuentros interesantes.

No tenemos, entonces, aquí verdadera literatura de viaje, sino una serie de menciones casuales de topónimos y movimientos geográficos realistas, que tenemos que descubrir en un fárrago de episodios aventurosos de los héroes cervantinos. "La acción - como bien dijo Joaquín Casalduero - se interna más aún en la vida, aumentándose, por lo tanto, la inverosimilitud, compitiendo la realidad con la imaginación en crear mil casos sorprendentes". ${ }^{16}$

El Persiles no es, en realidad, el palimsesto del viaje de Cervantes a Italia que esperábamos descubrir. El análisis de cualquier de las Novelas ejemplares ${ }^{17}$ bajo el sentido de la relación de viaje, y en particular del viaje a Italia, podría quizás mostrarnos algunos aspectos autobiográficos del viaje cervantino. Es posible que esos detalles sean notas autobiográficas del mismo Cervantes, pero aquí tenemos que subrayar que ya son parentéticas, como en el Persiles, a las visicitudes de los personajes de las novelas. Tendremos por lo tanto que analizar el subtexto cervantino para buscar "otro" diario del viaje a Italia, el diario de aventuras marineras que el autor nunca escribió.

El itinerario de Tomás Rodaja, el licenciado Vidriera de la novela homónima, empieza en la carretera entre Málaga y Toledo con el encuentro casual de un "gentilhombre a caballo, vestido bizarramente de camino". La carretera me parece aquí tener la importancia de un personaje verdadero. 
La conversación que se entabla entre Tomás y el capitán Don Diego de Valdivia es una invitación al viaje hecha por un experto que sabe pintar al vivo para el estudiante las bellezas de Italia y la libertad de la vida militar en la Península. Como en todos los diarios de viaje a Italia, esta conversación es el prólogo al viaje mismo, un catálogo de todas las razones estéticas (y también de las económicas y culinárias) que hacen absolutamente necesaria la visita a la Península. "La belleza de la ciudad de Nápoles" precede directamente "las holguras de Palermo", "la abundancia de Milán" y "los festines de Lombardía": esos son elementos estéticos, pero también detalles importantes y notas de exuberancia económica y de florecimiento general del paisaje y de la vida en Italia. En ellos podemos notar por supuesto detalles gastronómicos que se manifiestan esenciales en la elección de Tomás. La apología de Italia que ofrece don Diego de Valdivia está hecha con una perfecta coordinación psicológica: el capitán sabe dar el último toque a su fabuloso discurso. No se debe olvidar que el encuentro tiene lugar "al bajar de la cuesta de la Zambra, camino de Antequera": un lugar que sin duda no puede compararse a la Italia de la cual don Diego está hablando. Todos los viajeros de ese período conocen muy bien, jay!, la pobreza de las ventas y las restricciones culinarias de la vida en las carreteras de Castilla." "La venta castellana", escribe Agustín Gonzáles, "en general es pobre, sucia, incómoda y mal provista. [...] Como si fuera poco, la comida es escasa y mal acondicionada las más veces". $Y$ así sucesivamente. Por estas razones, yo creo, el elogio de la vida en Italia se dirige dentro de poco a las "espléndidas comidas de las hosterías" de Italia, seguida por muy animadas alusiones (es el tono "hablado" en un trasfondo de tonos de rápida inmediación que podría recordar la publicidad de la televisión), y por un pastiche lingüístico de la vida de las tabernas italianas que deja sonante el pobre y sediento Tomás: "aconcha, patrón; pasa acá, manigoldo; venga la macarela, li polastri, e li macarroni". Esa es la intertextualidad misma que nos recuerda el fabuloso e imaginario "paese di Bengodi" que describe Maso del Saggio a Calandrino en una novela del Decameron (VIII, 3): la atracción del olor que el recuerdo de la cocina ejerce sobre el sediento Tomás constituye un chantaje poderoso, y no debe sorprendernos que esta directa alusión a la vida libre y a la abundancia de la comida en las tabernas italianas que "la discreción de nuestro Tomás Rodaja [comience] a titubear", exactamente como la del Calandrino de la novela de Boccaccio frente a las hiperbólicas seducciones de Maso.

$\mathrm{Y}$ así la curiosidad de ver, a la cual se añade, lo que es importante, la invitación a la mesa de don Diego, tienen la ventaja sobre la preocupación de 
la interrupción de los estudios de Tomás: por supuesto, lo sabemos, "las luengas peregrinaciones hacen a los hombres discretos" 19 y la pérdida de "tres o cuatro años" no le parece un problema grave, frente a un viaje tan importante a través de "Italia y Flandes y otras tierras y países". Con la pequeña donación que le dieron los estudiantes que en Salamanca lo habían empleado como paje, Tomás Rodaja puede permitirse tres años de independencia económica. ${ }^{20}$ Entonces Tomás llega a Italia en "cuatro galeras de Nápoles", el medio de transporte más común en esta época para los viajeros españoles. Es muy interesante leer el diario que nos dejó un anónimo francés acerca de su viaje a Italia por mar en 1588-1589. ${ }^{21}$ Pero el texto cervantino nos ofrece detalles extraordinarios de la vida a bordo de un barco en el Mediterráneo, esta "estraña vida de aquellas marítimas casas" donde "lo más del tiempo maltratan las chinches, roban los forzados, enfadan los marineros, destruyen los ratones y fatigan las maretas". El anónimo francés nos ofrece también el tema muy común de un tremendo vendaval en el golfo del León: barcos que se perdieron, arrojados por la fuerza del aquí y allá en el Mediterráneo. Un barco va a parar en Córsega y otro a Tolón. ${ }^{22}$

En Génova empieza verdaderamente el viaje a Italia de Cervantes: "Hermosa y bellísima ciudad", Génova ofrece al extranjero que la vee por primera vez una cornucopia de atracciones: mujeres con el cabello artificialmente rubio ("los rubios cabellos de las genovesas", II, 48), ${ }^{23}$ caballeros muy elegantes, calles y plazas y palacios fabulosos. Y, con el topos de la belleza físi$\mathrm{ca}$, vuelve el de la comida abundante. Un catálogo de vinos extraordinarios, que podría hacer palidecer el recuerdo de los de Ribadavia y de Descargamaría: Trebbiano, Montefiascone, vinos griegos muy dulces, Cinqueterre, Vernaccia, Chentola, vinos blancos dei Castelli Romani, un grand tour enológico, una enciclopedia de los vinos del siglo XVI en la cual sin duda no pueden olvidarse los elementos autobiográficos de lo que vio e hizo (visa atque acta, o, si prefieren, bibita). ${ }^{24}$

Desde Génova, después de dejar a su amigo capitán que llega a Flandes, Cervantes no cambia el itinerario tradicional del tour que escribieron los extranjeros del siglo XVI. Dejando que las galeras prosiguieran su viaje por la costa hacía Nápoles, el viajero prefiere continuar por tierra su viaje de descubrimiento de este nuevo mundo y llega a Lucca, una ciudad tradicionalmente amiga de los españoles ("mejor que en otras partes de Italia son bien vistos y agasajados"). Florencia no comociona a Cervantes, lo que me parece extraño, a pesar de que se quedó allá cuatro días: ${ }^{25}$ la descripción superficial que Cervantes nos deja de esta ciudad es la misma que podría 
darse de muchas ciudades de Italia: "Contentóle Florencia en extremo, así por su agradable asiento como por su limpieza, sumptuosos edificios, fresco río y apacibles calles" (II, 49). Pero es Roma, "reina de las ciudades y señora del mundo", la ciudad que atrae la atención del viajero Tomás:

Visitó sus templos, adoró sus reliquias y admiró su grandeza: y así como por las uñas del león se viene en conocimiento de su grandeza y ferocidad,así él sacó la de Roma por sus despezados mármoles, medias y enteras estatuas, por sus rotos arcos y derribadas termas, por sus magnificos pórticos $\mathrm{y}$ anfiteatros grandes, por su famoso y santo río, que siempre llena sus márgenes de agua y las beatifica con las infinitas reliquias de cuerpos de mártires que en ella tuvieron sepultura (II, 49).

Roma antigua, Roma cristiana, Roma del Renacimiento, una ciudad llena de "grandeza y majestad", un centro donde convergen "gentes y naciones". Roma todavía no puede compararse con Nápoles, "ciudad a su parecer y al de todos cuantos la han visto, la mejor de Europa, y aun de todo el mundo". Pero aquí el diario de viaje empieza a tomar forma telegráfica: Tomás llega de repente a Sicilia, vuelve a Nápoles y a Roma, llega a Loreto, Ancona y Venecia. Esta ciudad todavía tiena una breve descripción:

Parecióle que su riqueza era infinita, su gobierno prudente, su sitio inespugnable, su abundancia mucha, sus contornos alegres, $y$, finalmente, toda ella en sí y en sus partes digna de la fama que de su valor por todas las partes del orbe se extiende, dando causa de acreditar más esta verdad la máquina de su famoso arsenal, que el el lugar donde se fabrican les galeras, con otros bajeles que no tienen número.

Una última alusión a Milano, "oficina de Vulcano, ojeriza del reino de Francia, ciudad, en fin, que puede decir y hacer", ahora posesión del imperio español. Aquí el grand tour del Licenciado/Cervantes se acaba: desde Asti Cervantes llegará con su capitán a Flandes y volverá después a Salamanca para completar sus estudios.

Si el viaje a Italia de Tomás no refleja lo que normalmente puede considerarse el itinerario por tierra que Cervantes realizó con el cardenal Acquaviva, equivale no obstante, por su precisión geográfica, a un verdadero diario de viaje a Italia. Lo que ahora nos invita a preguntar es cómo Cervantes pudo describir con tanta precisión y verosimilitud el viaje por mar que, según su biografía, Cervantes no pudo hacer.

Una respuesta podría hallarse en la fecha de composición del Persiles, casi cincuenta años despues del viaje a Italia de Cervantes. ¿ Es posible que los 
recuerdos personales de su viaje fueran totalmente aniquilados? ¿Y que habia terminado la descripción de su itinerario marino sirviéndose de relatos de viajes (orales o escritos) de amigos o de diarios impresos? Al fin y al cabo, en un período histórico tan vivaz de movimientos geográficos, el número de viajeros españoles que se embarcaban por Italia y que, privadamente, escribían sus recuerdos debía ser muy grande.

De todas maneras, quizás, tenemos aquí que poner en duda los detalles del itinerario de la vuelta a Italia del legado Acquaviva. No es imposible que los archivos romanos nos permitieran descubrir nuevos datos (quizás, incluso el relato del viaje mismo) y que podamos encontrar nuevas respuestas, más precisas, a las preguntas que nos han motivado las descripciones del viaje a Italia de las Novelas ejemplares de Cervantes. 


\section{NOTAS}

1 Véase el capítulo "Viajeros españoles y italianos" en el ensayo de Ángel Gómez Moreno, España y la Italia de los bumanistas: primeros ecos (Madrid, Editorial Gredos, 1994), pp. 296-314, en el cual se habla de "la abundante documentación que permanece intacta en nuestras bibliotecas".

2 "The most direct and personal means of diffusing humanism" ("The Spread of Italian Humanism" en Goodman y Mackay, The Impact of Humanism...), p. 3.

3 En el prólogo a su Interpretación de las palabras castellanas en lengua latina (Salamanca, ca. 1495).

4 A. Gómez Moreno, p. 312.

5 Madrid, Aguilar, 1952.

6 Don Quijote, II, vI.

7 Cervantes, "La ilustre fregona". "La tipologfa literaria de la Edad de Oro describe una curva cerrada que va del caballero al pastor, al picaro y al peregrino, donde los extremos se tocan, porque el peregrino es el caballero y la aventura se expresa en sus dimensiones humanas" (Juan Bautista Avalle-Arce en su introducción a Los trabajos de Persiles y Sigismunda Madrid, Clásicos Castalia, 1969, p. 24).

8 Giulio Acquaviva d'Aragona (1546-1574) fue un brillante ecclesiástico de Napoles, y tenfa a penas 22 ahios cuando Pio v lo envió nuncio extraordinario a la corte de Madrid (1568), para tratar, entre otros importantes negocios, él de la bola para la crusada contra los Turcos y por lo mismo informarse discretamente sobre la muerte de don Carlos. Acquaviva llego a Italia en diciembre del mismo afío, seguido por Cervantes que quedó algunos meses, y poco despues fue creado cardinal en el 1570 (Dizionario biografico degli Italiani, 1, 197).

9 No hemos podido hallar ningun documento de éso itinerário en los papeles del legado Acquaviva. Martin Ferreiro en su "Bosquejo de los viajes de Cervantes" (en el texto de Manuel de Foronda, Cervantes viajero con un prólogo de D. Cayetano Rosell y un mapa con los viajes de Cervantes. Madrid, Imprenta de Fortanet, 1880) afirma categoricamente que podrfa ser un viaje por tierra. El viaje del legado en Francia y en España está my bien documentado en la obra Il Burattino veridico, overo Instruzione generale per chi viaggia, escrito por Giuseppe Miselli, llamado "il Burattino", que per más de trenta afios due el corrier del papa (Roma, Michel'Ercole, 1682), pp. 217-219. Eso trata de viajes por mar, de Civitavecchia hasta Barcellona, mas rápido y cómodo del itinerario terra.

10 Un mercante di Milano in Europa: diario di viaggio del primo Cinquecento, édito por L. Monga (Milano, Edizioni Universitarie Jaca, 1985).

11 "Por lo mismo que todavia no tiene un temperamento artístico claro, puede darse cuenta con exactitud y provecho de las impresiones que la tierra, los hombres y las ciudades le producen" (Francisco Navarro y Ledesma, El ingenioso bidalgo Miguel de Cervantes Saavedra. Madrid, Imprenta Alemana, 1905, p. 76).

12 Juan Bautista Avalle-Arce en su introducción a los Trabajos de Persiles y Sigismunda, p. 20.

13 Véase, por ejemplo, J. Granados, "Ricordi geografici d'Italia nell'opera cervantina", Quaderni ibero-americani, XXX-XXXII (1965), 397-404.

14 No puede encontrarse ninguna alusión a Florencia en del Persiles: desde Lucca (p. 412) pasamos de repente a Acquapendente, "lugar cercano de Roma" (p. 413).

15 Este camino estaba tan diffcil y peligroso por la presencia de brigantes: uel gran viajero que fue Montaigne se quedó miedoso: "la strada di Genoa a Milano non era troppo sicura di ladri" (Vournal de voyage, éd. F. Rigolot. Paris, Presses Universitaires de France, 1992), p. 217.

16 Joaquín Casalduero, Sentido y forma de "Los trabajos de Persiles y Sigismunda" (Madrid, Gredos, 1975), p. 182.

17 Siguo el texto de la obra, édito por Harry Sieber (Madrid, Cátedra, 1994). 

y 1618)" que será publicado en los actos del II $^{\circ}$ Congreso internacional sobre Caminería Hispanica, que tuvo lugar a Madrid, Alcalá de Henares, Pastrana y Guadalajara despues el 4 hasta al 9 de julio de 1994. Cfr. también Agustín Gonzalez de Amueza y Mayo, "Como se viajaba en el siglo XVI", en Opuisculos histórico-literarios, III (Madrid, C.S.I.C., 1953), Pp. 212-226.

Ha sido observado que el viaje de Tomás Rodaja no lo hace "discreto", si se observa la conclusión de la novela (R. El Saffar, Novel to Romance: $A$ Study of Cervantes's Novelas ejemplares. Baltimore, The Johns Hopkins University Press, 1974, pp. 50-61; A. K. Forcione, Cervantes and The Humanist Vision: A Study of Four Exemplary Novels. Princeton, Princeton University Press, 1982, pp. 226-316). Tomás, dodavla, es un viajero inteligente que sin duda sabe extrapolar de la realidad superficial que observa ("asl como por las ufias del león se viene un conocimiento de su grandeza y ferocidad, así él sacó la de Roma por sus despedazados mármoles, por sus magnificos pórticos y anfiteatros grandes, por su famoso y santo rio").

20 Parece que en Italia el costo de la vida fuera más bajo que en España; entonces Tomás harla podido viver económicamente en manera indipendiente por mucho tiempo.

21 Véase la edición que di Voyage de Provence et d'Italie, 1588-1589 (Ginebra, Slatkine, 1994).

22 Esa es una situación verdadera y no un poncifliterario. Fernand Braudel describió documentos de archivo cque permiten de hacer una historia de los naufragios en el golfo del León en todo el siglo XVI (La Méditerrané et le monde méditerranéen à l'époque de Philippe II. Paris, Colin, 1982, I, 227-232): por ejemplo, el "coup de vent" del 19 de abril de 1569 que disperdió a través todo el Mediterráneo occidental (hasta la isla de Pantelleria) la escuadra de las galeras del Gran Comendador de Castilla que estabe cerca de Aigues-Mortes. Véase otra relación paralela en la edicion citada del texto anónimo del Voyage de Provence e d'Italie. "Le $2^{e}$ decembre audict an 1588 je fus adverty qu'il passoit vingt quatre galeres du roy d'Espagne qui alloient à Naples et qu'elles estoient aux Isles d'Or. Cela fust cause qu'aussitost les fus trouver et m'enbarquay pour retourner à Gennes, et pris le voiage de la mer tant à cause des neiges qui estoient aux montagnes que à cause des guerres de Provence. [...] Je estoie sur la galaire appellee l'Anuntiation, qui estoit celle qui suivoit le capitaine et general de toutes les galaires. $Y$ estoit le cardinal de Mandosse, qui alloit a Rome, protecteur de la nation d'Espagne, son nepveu, le conte et la contesse de Trimonse alloient a Thurin voir l'Infante d'Espagne. De toutes ces galaires estoit general le seigneur dom Pedro de Leira. Il y avoir sur les galaires vingt compagnies de gens de pied, quarente chevaux d'Espagne et à chacune galaire quatre pieces des canon de baterie, 30 rames de chacun costé et environ 260 esclaves turcs, estans en resolution de donner jusques à Gennes, où l'on compte trois cens mil et plus de Marseille, qui vallent cent lieues de France. Le $\mathbf{4}^{\mathbf{e}}$ jour, qui estoit Ste Barbe, la tempeste fust si grande que toutes les galaires penserent perir tout à ung instant. Nous avions desja passé Toulon et la Ciotat et estions loing du port de Villefranche environ quatre vingtz mil. La tempeste dura sans discontinuer plus de 28 heures; elle fust si grande que toutes les voilles furent mises en pieces, la plus part des arbres brisez et rompuz, le vent estoit si grand et les flotz de la mer que en ung instant toutes les galaires qui se suivoient les unes les autres furent separees et eslongnees, qu'elles furent trois jours sans se revoyr. L'on pensoit que tout fust perdu, l'on fust contrainct pour descharger les navires jecter en mer quelque meubles et plusieurs chevaux d'Espagne que le roy d'Espagne envoyoit à l'empereur et au duc de Savoye. La necessitté fust si grande que l'on fust contrainct gecter dans l'eau jusques aux barilz des esclaves et là où il mettent l'eau pour boire. Durant la tempeste le comitte, le pillotte et tous pillottes qui sont les principaux officiers d'une galaire, se trouverent si estonnez que tous ensemble resolurent de mettre nostre galaire en plaine mer et la laisser là à la misericorde de Dieu, ce qui fut faict à l'instant, mise en plaine mer sans sçavoir quelle routte l'on tenoit. Aucuns disoient que nous estions à la voye de Corse, les autres en Sardaigne, les autres y doubtoient. Voiant tout desesperé, chacun se mist en prieres, la plus part se confesserent à ung relligieux qu'ils appelloient padre commendadore de Naples, pensans mourir à toutes heures, car tantost nostre galaire demeuroit cambree en plaine mer et après rellevee par les flots. Les flotz estoient si grandz qu'aucunes fois il entroit dans la 
galaire à une fois plus de dix muyds d'eau. Chascun estoit si mouillé et trempé que l'on ne pourroit seicher. L'on vuidoit tousjours l'eau au mieux que l'on pouvoit. Nous estions si pressez dans la chambre de desoubz la porte que l'on se nuisoit les ungs soubz les autres. Nous y estions plus de sept vingtz, la plus part firent des voeux après leurs confession: moy mesme en ay faict. Pendant ceste tempeste la barque qui suivoit la galaire du general fust la premiere perdue. Il y avoit douze cens hommes dedans, qui furent submergez: il s'en perdit beaucoup d'autres. La barque de nostre galaire fust gectee dans la mer. Il se sauva ung homme lequel se mist sur ung baril d'un esclave, avec lequel il fust jusques au port.

Après la tempeste finye, l'on commença à s'apprester et regarder par la charte où nostre galaire pourroit estre et en quel endroit et destroit; et fust trouvé que nous estions à cent mil de Villefranche. L'on reprint cette routte et $y$ arrivames à ung petit voille que l'on remist au lieu de celuy qui avoit esté rompu, et ce avec grand peine, d'autant que les esclaves ne pouvoient plus ramer à cause du travail qu'ils avoient pris pendant la tempeste, sans manger n'y boire; comme aussi ilz ne pouvaient à cause que l'on avoit gecté l'eau dans la mer avec leurs barilz.

Enfin, nous arrivasmes à Villefranche et n'y trouvasmes qu'une galaire qui estoit la generalle, laquelle ne faisoit que d'arriver là. On attendit les autres et mismes pied à terre.

Véase la reacción del anónimo viajero del Voyage de Provence et d'Italie. "se font porter les gentilles dones dans des chaires couvertes de velours, satin et autre estoffe de couleurs, et sont leurs chaises ainsi portees par quatre hommes par la ville. Tous les samedis elles sont nues testes jusques à ce qu'elles ayent lavé leurs cheveux au soleil pour seicher: ce sont les plus beaux cheveux de toute l'Italie, aultant pauvres que riches."

24 Hoby emplea la misma estructura en su descripción de Nápoles. Asombrado por la "abundancia de comida", en particular de vinos, Hoby menciona algunos de esos vinos, casi gustándo el recuerdo de ellos: "vino Greco, a verie strongwine, which I beleve is so called bicause of Torre del Greco, where it is shipped to be transported unto Roome and other places, and not because yt cam owt of Greece, as some hold opinion; also Maniaguerra, a sweete wine of a verie highe color, Vernaccia, a strong headie wine, Romanesco, which is dronke for a delicate wine in wynter, Latino, which is a delicate small wine for sommer, and dyverse other" (Thomas Hoby, The Travels and Life of Sir Thomas Hoby, ed. E. Powell. London, The Royal Historical Society, 1902), p. 20.

25 Cervantes sigüe la tradición del viaje a Italia de su época, según la cual el viajero se queda a Génova sólo el tiempo necesario para descansarse psicológicamente, después las aventuras marinas; llega a Lucca y a Florencia, donde se queda cuatro o cinco días y sale rápidamente a Roma. 